\title{
Differences in aerosol absorption Ångström exponents between correction algorithms for a particle soot absorption photometer measured on the South African Highveld
}

\author{
J. Backman ${ }^{1}$, A. Virkkula ${ }^{1,2,3}$, V. Vakkari ${ }^{3}$, J. P. Beukes ${ }^{4}$, P. G. Van Zyl ${ }^{4}$, M. Josipovic ${ }^{4}$, S. Piketh ${ }^{4}$, P. Tiitta ${ }^{4,5}$, \\ K. Chiloane ${ }^{4,6}$, T. Petäjä ${ }^{1}$, M. Kulmala ${ }^{1}$, and L. Laakso ${ }^{3,4}$ \\ ${ }^{1}$ Department of Physics, University of Helsinki, Helsinki, Finland \\ ${ }^{2}$ Institute for Climate and Global Change Research, School of Atmospheric Sciences, Nanjing University, Nanjing, China \\ ${ }^{3}$ Finnish Meteorological Institute, Helsinki, Finland \\ ${ }^{4}$ Unit for Environmental Sciences and Management, North-West University, Potchefstroom, Republic of South Africa \\ ${ }^{5}$ Department of Environmental Science, University of Eastern Finland, Kuopio, Finland \\ ${ }^{6}$ Sustainability Division, Research, Testing and Development, Eskom Holdings SOC Ltd, Johannesburg, \\ Republic of South Africa
}

Correspondence to: J. Backman (john.backman@helsinki.fi)

Received: 30 June 2014 - Published in Atmos. Meas. Tech. Discuss.: 19 September 2014

Revised: 24 November 2014 - Accepted: 3 December 2014 - Published: 8 December 2014

\begin{abstract}
Absorption Ångström exponents (AAEs) calculated from filter-based absorption measurements are often used to give information on the origin of the ambient aerosol, for example, to distinguish between urban pollution and biomass burning aerosol. Filter-based absorption measurements are widely used and are common at aerosol monitoring stations globally. Several correction algorithms are used to account for artefacts associated with filter-based absorption techniques. These algorithms are of profound importance when determining the absolute amount of absorption by the aerosol. However, this study shows that there are substantial differences between the AAEs calculated from these corrections. Depending on the used correction, AAEs can change by as much as $46 \%$. The study also highlights that the difference between AAEs calculated using different corrections can lead to conflicting conclusions on the type of aerosol when using the same data set. The AAE ranged between 1.17 for non-corrected data to 1.96 for the correction that gave the greatest values. Furthermore, the study implies that the AAEs reported for a site depend on at which filter transmittance the filter is changed. In this work, the AAEs were calculated from data measured with a three-wavelength particle soot absorption photometer (PSAP) at Elandsfontein on the South African Highveld for 23 months. The sample
\end{abstract}

air of the PSAP was diluted to prolong filter change intervals, by a factor of 15 . The correlation coefficient between the dilution-corrected PSAP and a non-diluted Multi-Angle Absorption Photometer (MAAP) was 0.9. Thus, the study also shows that the applicability of the PSAP can be extended to remote sites that are not often visited or suffer from high levels of pollution.

\section{Introduction}

Atmospheric aerosols form part of the climatic system of the Earth. Aerosol light scattering, absorption or both will reduce solar insolation at the surface and alter the radiative transfer through the atmosphere. This is called the "direct radiative effect" of aerosols (Haywood and Boucher, 2000; Lohmann and Feichter, 2005). A strong light-absorbing particle species is black carbon (BC), which is a byproduct of incomplete combustion processes. A study by Bond et al. (2013) concluded that $\mathrm{BC}$ is the second most important positive radiative forcer. In the present study, the term BC will be used according to the definition of Bond et al. (2013), i.e. a material with specific properties. BC particles are made of spherules of mostly pure carbon that form aggregates. They absorb so- 
lar radiation with a weak spectral selectivity and are, therefore, black in appearance (Kirchstetter et al., 2004; Andreae and Gelencsér, 2006). However, not all light-absorbing particles are black in appearance. Some organic carbon (OC) containing aerosols have been shown to exhibit a spectral selectivity that exceeds that of $\mathrm{BC}$ particles. These particles are called brown carbon $(\mathrm{BrC})$ since they appear brownish to the eye and strongly absorb light at shorter wavelengths. $\mathrm{BrC}$ is a known constituent of biomass burning aerosol (Kirchstetter et al., 2004). In addition, desert dust can be a substantial constituent of total suspended particle mass, and dust absorbs light at short wavelengths (e.g. Prospero, 1999; Russel et al., 2010).

The extent to which light interacts with aerosol particles can be expressed by the scattering coefficient $\left(\sigma_{\mathrm{SP}}\right)$, absorption coefficient $\left(\sigma_{\mathrm{AP}}\right)$ and the extinction coefficient $\sigma_{\mathrm{EP}}$. The spectral dependence of light interaction can be described by the Ångström exponent (AE). By convention, $\mathrm{AE}$ is the negative slope of the wavelength dependency of the above coefficients in logarithmic space

$\ln \left(\sigma_{i}\left(\lambda_{i}\right)\right)=-\mathrm{AE} \ln \left(\lambda_{i}\right)+C$,

where $\sigma_{i}$ is the scattering, absorption or extinction coefficient at wavelength $\lambda_{i}$. When substituting $\sigma_{i}$ with $\sigma_{\mathrm{AP}}$ in Eq. (1), AE will represent the light-absorption Ångström exponent (AAE). Thus, AAE describes the spectral dependence of light absorption by the aerosol. The work by Moosmüller et al. (2011) provides a more in-depth view of its definition. When $\sigma_{i}$ is the substituted with $\sigma_{\mathrm{SP}}, \mathrm{AE}$ becomes the scattering Ångström exponent (SAE).

The wavelength dependence of light scattering and absorption is not only of climatic importance, it can also provide additional information on the aerosol size distribution and chemical composition (Bergstrom et al., 2007; Kirchstetter and Thatcher, 2012; Moosmüller et al., 2011; Schuster et al., 2006). The AAE of the aerosol can be used to differentiate between different sources of aerosols due to the differences in chemical composition that has an influence on aerosol light-absorption properties (e.g. Andreae and Gelencsér, 2006; Hoffer et al., 2006; Kirchstetter and Thatcher, 2012; Kirchstetter et al., 2004). The chemical composition of the absorbing aerosol does not exclusively determine the AAE since a non- or weakly absorbing coating can change the AAE of the aerosol (Gyawali et al., 2009; Lack and Cappa, 2010). However, AAEs have been used to distinguish between urban air pollution from biomass smoke (Clarke et al., 2007) and mineral dust events (Collaud Coen et al., 2004; Petzold et al., 2009). The spectral selectivity of absorption has also been used to estimate the contribution of absorption by OC in the aerosol (Kirchstetter and Thatcher, 2012).

Filter-based absorption measurement techniques are suitable for unattended use and are therefore widely used for measuring the $\sigma_{\mathrm{AP}}$ and $\mathrm{AAE}$ of the aerosol. However, filterbased absorption measurements suffer from undesired and inevitable interactions between the deposited sample and the optical characteristics of the filter (Collaud Coen et al., 2010). These characteristics and, therefore, artefacts constantly change as a pristine filter gradually becomes so aerosol-laden it needs to be changed.

Collimated light incident on the filter is subject to multiple scattering by the fibers in the filter. Consequently, the degree of collimation decreases as light penetrates into the filter. The optical path length through the filter will increase and thus enhance light absorption by the sample embedded in the filter. The deposition of light-scattering aerosols can also increase the optical path of the filter, and further enhance light absorption by the sample. In contrast, light-absorbing particles will reduce the optical path length and are primarily responsible for the reduction of light transmittance through the filter. Several studies have focused on minimising these artefacts empirically with correction algorithms or correction functions (e.g. Bond et al., 1999; Collaud Coen et al., 2010; Müller et al., 2014; Ogren, 2010; Petzold and Schönlinner, 2004; Virkkula et al., 2005). An essential part of these corrections is to compensate for the influence of the filter on the deposited sample that changes with the filter transmittance (Tr), which is referred to as the filter-loading correction function $f(\operatorname{Tr})$.

The need to use a filter-loading correction function is well established. However, the influence of correction algorithms on the AAE has not been evaluated. The primary objective of this study is to evaluate uncertainties involved with calculating AAE from $\sigma_{\mathrm{AP}}$ measured with filter-based measurement techniques that depend on correction algorithms. These uncertainties will also impinge on the assessment of the contribution of organics to light absorption. This study will focus specifically on the correction functions used for the particle soot absorption photometer (PSAP). Data gathered on the central Highveld in South Africa during the European Integrated Project on Aerosol Cloud Climate and Air Quality Interactions (EUCAARI) project was utilised (Laakso et al., 2012). In addition to the primary objective of this study, the performance of a dilution setup used for the PSAP to prolong filter change time will be evaluated. The evaluation was done by comparing the diluted PSAP with a non-diluted MultiAngle Absorption Photometer (MAAP).

\section{Methods and measurements}

\subsection{Measurement site}

The data used in this study comprise 23 months of measurements conducted at Elandsfontein on the central Highveld in South Africa from February 2009 to January 2011. A study by Laakso et al. (2012) already provides a comprehensive overview of the site; hence, the description of the site is brief.

Figure 1 depicts the location of the Elandsfontein measurement station $\left(26^{\circ} 14^{\prime} 43^{\prime \prime} \mathrm{S}, 29^{\circ} 25^{\prime} 30^{\prime \prime} \mathrm{E}\right)$. The station is located on the South African Highveld, which is an in- 


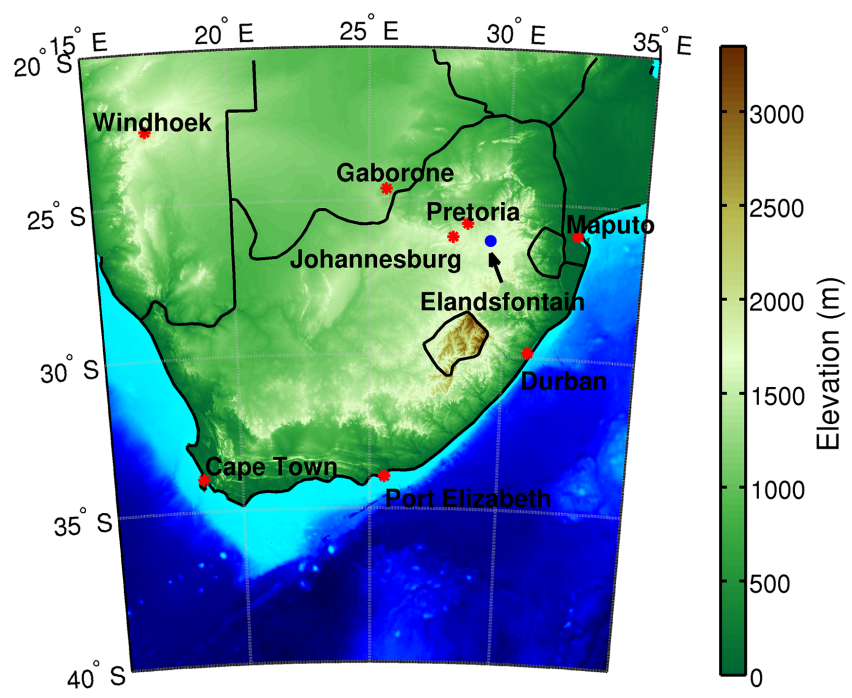

Figure 1. Map of South Africa and the location $\left(26^{\circ} 14^{\prime} 43^{\prime \prime} \mathrm{S}\right.$, $29^{\circ} 25^{\prime} 30^{\prime \prime} \mathrm{E}$ ) of the Elandsfontein measurement station on the South African Highveld. The figure is based on the ETOPO1 bedrock data set (Amante and Eakins, 2009).

land plateau that covers approximately $30 \%$ of the surface area of South Africa. The site was located $1750 \mathrm{~m}$ above mean sea level (a.m.s.l.), with surrounding areas that range from 1400 to $1600 \mathrm{~m}$ a.m.s.l. (Laakso et al., 2012). Elandsfontein is within the Mpumalanga Province and the site surrounding comprise a variety of industrial activities, which include nine coal-fired power plants, a petrochemical plant and various pyrometallurgical smelters. In addition, other anthropogenic sources include traffic emissions and domestic combustion for heating and cooking. The densely populated Gauteng Province is located west of Elandsfontein where the Johannesburg-Pretoria conurbation is situated $(\sim 140 \mathrm{~km}$ from Elandsfontein), as well as other industrial regions. A more detailed description of the site and a synopsis of meteorological conditions are presented by Laakso et al. (2012) and references therein.

\subsection{Instruments}

The instruments were connected to a Rupprecht and Patashnick $\mathrm{PM}_{10}$ inlet, and the sample aerosol was dried using a self-regenerating silica gel drier (Tuch et al., 2009). In addition to the $3 \lambda$ PSAP (Radiance Research, Seattle) and the MAAP (Model 5012, Thermo Scientific), a three-wavelength nephelometer (Aurora 3000, Ecotech) was used to measure $\sigma_{\text {SP. }}$ All measurements were converted to STP conditions $\left(0^{\circ} \mathrm{C}\right.$ and $\left.1013 \mathrm{hPa}\right)$. The scattering coefficients were additionally corrected for truncation according to Müller et al. (2011a) and interpolated to the PSAP wavelengths.

The instruments measure at different wavelengths. Therefore, the data needs to be interpolated or extrapolated to the same wavelengths. The interpolation (or extrapolation) was

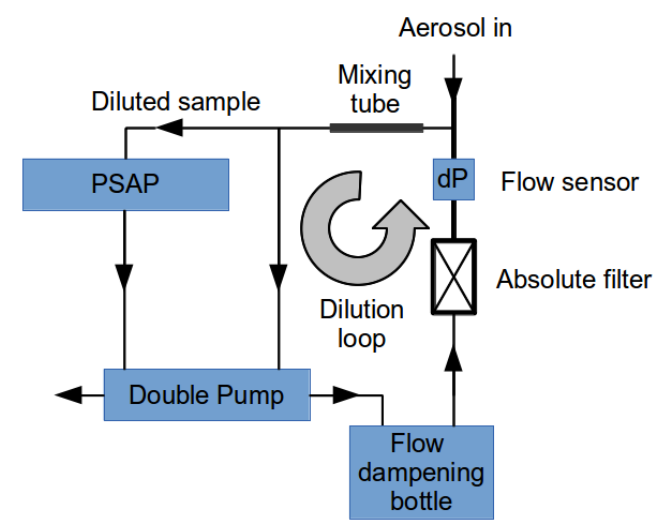

Figure 2. Simplified schematics of the sample air dilution loop used to prolong filter change intervals.

done using the AE between two wavelengths $\left(\lambda_{1}\right.$ and $\left.\lambda_{2}\right)$ closest to the desired wavelength $\left(\lambda_{x}\right)$ as $\sigma_{x}=\sigma_{1}\left(\lambda_{1} / \lambda_{x}\right)^{\mathrm{AE}}$, where $\sigma_{1}$ is the spectrally closest light-scattering or lightabsorption coefficient. The PSAP provides light-absorption measurements at 467, 530 and $660 \mathrm{~nm}$ wavelengths whereas the MAAP is a single-wavelength instrument $(637 \mathrm{~nm})$ (Müller et al., 2011b), and thus cannot provide AAEs. The comparison between the instruments in the following chapters was done by interpolating the PSAP data to the wavelength of the MAAP. The Nephelometer measured light scattering at 450, 525 and $635 \mathrm{~nm}$ wavelengths (Müller et al., 2011a). These measurements were interpolated and extrapolated to the PSAP wavelengths and the MAAP wavelength. All of the interpolation (or extrapolation) to match the wavelengths of the other instrument was done using the momentary AE of the data.

The PSAP filters are changed manually, and this should be done before they get too heavily loaded. At background sites, this is not a problem, but at polluted sites such as Elandsfontein, the filters may have to be changed several times per day. Due to logistical reasons, the sample flow was diluted using the setup depicted in Fig. 2 to prolong the need to change filters. The dilution was arranged by mixing the sample air flow with particle-free filtered air. The flow made a loop from a Thomas membrane pump through a flow fluctuation dampening chamber to an absolute filter, to the mixing tube and back to the pump. The dilution flow was tracked by measuring the pressure drop over a constriction in the dilution loop. The typical dilution and sample flows were 10 and 0.71 per minute $(\mathrm{lpm})$. The flow rates of the dilution loop were checked manually when the filters were changed.

\subsection{Calculation methods}

\subsubsection{Preprocessing}

The basics of filter-based absorption measurements are straightforward, whereas the samples interactions with the 
filter matrix are not (Müller et al., 2014). Aerosol particles in a known volume of air deposit onto a fiber filter as the sample passes through the filter. The deposition of particles onto the filter-matrix will decrease the transmittance of light through the filter. The Bouguer-Lambert-Beer law states that the attenuation of light in a medium will decrease exponentially from the initial intensity $\left(I_{0}\right)$ to the transmitted intensity $\left(I_{\mathrm{t}}\right)$ in a given path length. By choosing $I_{0}$ as the intensity transmitted by a pristine filter, the interaction with light by the filter itself will initially be avoided. Thus, the change in the transmittance yields the uncorrected absorption coefficient $\left(\sigma_{0}\right)$ of the deposited aerosol. For subsequent measurements, $\sigma_{0}$ can be written as

$\sigma_{0}=\frac{A}{Q \cdot \Delta t} \ln \left(\frac{I_{t-\Delta t}}{I_{t}}\right)$.

In Eq. (2), the sample spot size $(A)$, sample flow rate $(Q)$ and the time elapsed $\Delta t$ represent the length of the sample-air column drawn through the filter. A more detailed derivation of the equation has been done by, e.g. Weingartner et al. (2003). There are several assumptions associated with Eq. (2), as pointed out by Moosmüller et al. (2009), which will result in artefacts. The correction for inherent systematic errors, such as spot size correction and flow calibration, should be done on $\sigma_{0}$, not at a later stage in the data post-processing. The studies by Bond et al. (1999) and Ogren (2010) describe how to correct for systematic errors in more detail. In this work, $\sigma_{0}$ was calculated from the PSAP raw data by integrating the signal and reference counts over $1 \mathrm{~h}$ periods and not by averaging the $1 \mathrm{~s}$ absorption coefficients as calculated by the instrument. This results in clearly lower noise and detection limits (Springston and Sedlacek, 2007).

At this step, the calculated $\sigma_{0}$ was that after the dilution, here $\sigma_{0, \mathrm{DIL}}$. The relationship between the $\sigma_{0, \mathrm{DIL}}$ and the actual absorption coefficient of the sample $\left(\sigma_{0, \mathrm{~S}}\right)$ entering the mixing tube prior to dilution is

$\sigma_{0, \mathrm{~S}}=\sigma_{0, \mathrm{DIL}}\left(1+\frac{Q_{\mathrm{DIL}}}{Q_{\mathrm{S}}}\right)$,

where $Q_{\mathrm{DIL}}$ is the dilution flow and $Q_{\mathrm{S}}$ is the sample flow into the mixing tube. For clarity, the subscripts used in Eq. (3) are explicitly expressed here. If not explicitly stated otherwise, then $\sigma_{0}$ refers to $\sigma_{0, S}$.

The noise of $\sigma_{0, \mathrm{~S}}$ can be estimated using the propagation of uncertainty as follows:

$\delta \sigma_{0, \mathrm{~S}}=\sqrt{\sum_{i}\left(\frac{\partial \sigma_{0, \mathrm{~S}}}{\partial x_{i}}\right)} \delta x_{i}^{2}$.

The relative uncertainty of $\delta \sigma_{0, \mathrm{~S}} / \sigma_{0, \mathrm{~S}}$ can then be written, after some rearrangements, in terms of the $Q_{\mathrm{DIL}}$ and $Q_{\mathrm{S}}$, and their uncertainties ( $\delta Q_{\mathrm{DIL}}$ and $\delta Q_{\mathrm{S}}$ ) as follows:

$$
\frac{\delta \sigma_{0, \mathrm{~S}}}{\sigma_{0, \mathrm{~S}}}=\frac{Q_{\mathrm{DIL}}}{Q_{\mathrm{S}}+Q_{\mathrm{DIL}}} \sqrt{\left(\frac{\delta Q_{\mathrm{DIL}}}{Q_{\mathrm{DIL}}}\right)^{2}+\left(\frac{\delta Q_{\mathrm{S}}}{Q_{\mathrm{S}}}\right)^{2}},
$$

given that the uncertainty of the diluted sample $\left(\delta \sigma_{0, \mathrm{DIL}}\right)$ is insignificant in comparison to $\delta Q_{\mathrm{DIL}}$ and $\delta Q_{\mathrm{S}}$. For an integration time of $1 \mathrm{~h}$, used in the present study, this certainly holds true since $\delta \sigma_{0, \text { DIL }}$ is many orders of magnitude lower than the uncertainties of the dilution flows. Springston and Sedlacek 2007 gives the equation for $\delta \sigma_{0, \mathrm{DIL}}$ as $10^{(-0.60-1.31 \cdot \log (\Delta t))}$, which is less than $0.01 \mathrm{Mm}^{-1}$ for averaging times longer than $100 \mathrm{~s}$.

The relative uncertainty using Eq. (5) was estimated to be $\sim 0.039$, using the following values (in litres per minute): $Q_{\mathrm{DIL}}=10, Q_{\mathrm{S}}=0.70, \delta Q_{\mathrm{DIL}}=0.3$, and $\delta Q_{\mathrm{S}}=0.02$. The respective values represent the flow rates $\left(Q_{\mathrm{DIL}}\right.$ and $\left.Q_{\mathrm{S}}\right)$ and the standard deviation ( $\delta Q_{\mathrm{DIL}}$ and $\delta Q_{\mathrm{S}}$ ) calculated from the data set.

The dilution flow of the system was tracked by measuring the pressure drop over a constriction in the dilution loop and flows were checked manually on a regular basis. Data associated with significant deviations or fluctuations from the desired $Q_{\mathrm{DIL}}$ value were omitted, given that dilution flow deviated by more than $5 \%$ from the desired value. On average, the value of $\sigma_{0, \mathrm{DIL}}$ - the signal of the instrument after dilution - was $1.38 \mathrm{Mm}^{-1}$. Less than $3 \%$ of the $\sigma_{0, \mathrm{DIL}}$ data was below $0.01 \mathrm{Mm}^{-1}$.

\subsubsection{Absorption coefficients and Ångström exponents}

The actual absorption coefficient $\sigma_{\mathrm{AP}}$ is calculated by combining $\sigma_{0}$ with the scattering coefficients obtained from the nephelometer. There exist two widely used correction methods: the function originally presented by Bond et al. (1999) and the algorithm presented by Virkkula et al. (2005). These two will be used in the present paper. The constrained two-stream (CTS) radiative transfer algorithm presented by Müller et al. (2014) was not applied in this work.

The purpose of the correction algorithms is to compensate for interactions between the deposited sample onto the filter and the filter matrix. The method presented by Bond et al. (1999) was further clarified in the study by Ogren (2010). The correction functions of Bond et al. (1999) and Ogren (2010) (hereafter O2010) can be written as

$\sigma_{\mathrm{AP}}=f(\operatorname{Tr}) \sigma_{0}-s \cdot \sigma_{\mathrm{SP}}$,

where $\sigma_{\mathrm{AP}}$ is the corrected light-absorption coefficient. The subtraction on the right-hand side of the equation is the fraction $s$ of light-scattering coefficients $\left(\sigma_{\mathrm{SP}}\right)$ interpreted as absorption by the instrument, also called apparent absorption. The $02010 f(\operatorname{Tr})$ function is calculated with the equation

$f(\operatorname{Tr})=\left(k_{\mathrm{a}} \operatorname{Tr}+k_{\mathrm{b}}\right)^{-1}$.

The terms $k_{\mathrm{a}}$ and $k_{\mathrm{b}}$ are the empirically derived constants 1.5557 and 1.0227, respectively (Virkkula, 2010). The O2010 correction function has been characterised in the transmittance range of 0.7-1.0 (Bond et al., 1999).

Virkkula et al. (2005), hereafter referred to as V2010 due to an erratum by Virkkula (2010), modified the single- 
wavelength PSAP to measure light-absorption coefficients at three wavelengths $(467,530$ and $660 \mathrm{~nm})$. The V2010 algorithm differs from that of $\mathrm{O} 2010$ since it also takes the singlescattering albedo $\left(\mathrm{SSA}=\sigma_{\mathrm{SP}} /\left(\sigma_{\mathrm{SP}}+\sigma_{\mathrm{AP}}\right)\right)$ of the aerosol into account and uses a logarithmic loading correction function, which is

$$
f(\operatorname{Tr})=k_{0}+k_{1}\left(h_{0}+h_{1} \mathrm{SSA}\right) \ln (\mathrm{Tr}) .
$$

The constants $\left(k_{0}\right.$ and $\left.h_{0}\right)$ and coefficients $\left(k_{1}\right.$ and $\left.h_{1}\right)$ in Eq. (8) are different for each of the instruments wavelength (Virkkula, 2010), but also average values of all wavelengths were reported which are also included in the analysis (hereafter V2010avg). The study also reported different values for $s$ in Eq. (6) for the different wavelengths. In the second term on the right-hand side of Eq. (8), $h_{0}$ and $h_{1}$ corrects for the cross-dependency between $k_{1}$ and SSA. Explicitly, the multiple scattering correction, inherently included in the function $f(\operatorname{Tr})$, depends on the SSA of the aerosol and the filter transmittance in the algorithm. The filter transmittance range of the V2010 correction was characterised in the range of 0.41.0 and thus the V2010 correction is defined for a wider filter transmittance range than the $\mathrm{O} 2010$ correction. After calculating the absorption coefficients at the three PSAP wavelengths with the different methods, the AAE was calculated both for $\sigma_{\mathrm{AP}}$ and $\sigma_{0}$ using Eq. (1).

In addition, AAEs were also calculated from transmittances at the three PSAP wavelengths. The attenuation of light in the filter (ATN) was first calculated as

$\operatorname{ATN}(\lambda)=-100 \ln (\operatorname{Tr}(\lambda))$.

Next, AAE of ATN was calculated using Eq. (1) by substituting $\sigma_{i}(\lambda)$ with $\operatorname{ATN}(\lambda)$. This was done to make the analyses as comparable as possible with the studies of Kirchstetter and Thatcher (2012) who took filter samples and analysed them using spectrometers in transmission mode to determine the $\operatorname{AAE}$ from $\operatorname{ATN}(\lambda)$. The AAE calculated from ATN are profoundly different since the ATN is not measured incrementally as is the case for $\sigma_{0}$ and $\sigma_{\mathrm{AP}}$. The AAE of ATN at a certain $\mathrm{Tr}$ is the result of all deposited particles onto the filter prior to a specific $\operatorname{Tr}$ value.

\subsubsection{Estimation of the contribution of $\mathrm{OC}$ to absorption}

AAEs can also be used to estimate the contribution of OC to aerosol light absorption (Kirchstetter and Thatcher, 2012). Light absorption by OC occurs at the lower end of the visible spectrum and in the UV spectrum (Kirchstetter and Thatcher, 2012; Schnaiter et al., 2006). Since OC absorbs predominantly at short wavelengths, the presence of OC will increase the AAE; the AAE of $\mathrm{BC}$ is here attributed a value of unity. By attributing all light absorption at $660 \mathrm{~nm}$ to $\mathrm{BC}$, one can extrapolate the absorption of $\mathrm{BC}$ to shorter wavelengths using the AAE of BC. The absorption of OC is then the difference between the measured absorption and the contribution to absorption by $\mathrm{BC}$ as defined above. The work by Kirchstetter and Thatcher (2012) gives the equation for the contribution of OC to ATN (ATN $\mathrm{OC}$ ) as follows:

$\operatorname{ATN}_{\mathrm{OC}}(\lambda)=\operatorname{ATN}(\lambda, \operatorname{AE})-\operatorname{ATN}_{\mathrm{BC}}(\lambda, \operatorname{AE}=1)$.

The same approach can further be extended to include $\sigma_{\mathrm{AP}}$ values derived from the correction algorithms. Equation (10) then becomes

$\sigma_{\mathrm{AP}, \mathrm{OC}}(\lambda)=\sigma_{\mathrm{AP}}(\lambda, \mathrm{AAE})-\sigma_{\mathrm{AP}, \mathrm{BC}}(\lambda, \mathrm{AAE}=1)$,

where $\sigma_{\mathrm{AP}, \mathrm{OC}}$ stands for the amount of light absorption by OC after subtracting the contribution to light absorption by $\mathrm{BC}\left(\sigma_{\mathrm{AP}, \mathrm{BC}}\right)$ with an $\mathrm{AAE}=1$. It should be noted, however, that this is an approximation that does not take into account the mixing state of the $\mathrm{BC}$ aerosol particles (Lack and Langridge, 2013).

The fraction of filter attenuation due to $\mathrm{OC}$ at different wavelengths was then calculated using Eq. (12a)

$$
\begin{aligned}
f_{\mathrm{OC}}(\mathrm{ATN}) & =\frac{\operatorname{ATN}_{\mathrm{OC}}(\lambda)}{\operatorname{ATN}(\lambda)}, \\
f_{\mathrm{OC}}(\mathrm{abs}) & =\frac{\sigma_{\mathrm{AP}, \mathrm{OC}}(\lambda)}{\sigma_{\mathrm{AP}}(\lambda)},
\end{aligned}
$$

as given by Kirchstetter and Thatcher (2012). To extend this approach to light-absorption measurements using the different correction algorithms, ATN $\mathrm{OC}_{\mathrm{C}}$ in Eq. (12a) was substituted with $\sigma_{\mathrm{AP}, \mathrm{OC}}$ and ATN with $\sigma_{\mathrm{AP}}$, resulting in Eq. (12b).

\subsubsection{MAAP data processing}

The MAAP was used in the study as a reference to the diluted PSAP. However, the MAAP cannot be considered to be a true reference because it is also a filter-based measurement technique. Furthermore, the MAAP is know to have a cross-dependency to light-scattering aerosol and so does the PSAP (Müller et al., 2011b). The reference instrument should ideally retrieve light-absorption coefficients from suspended particles, such as extinction-minus-scattering or photoacoustic light-absorption measurements (e.g. Lack et al., 2006). However, these instruments were not available for the present study. The MAAP is a single-wavelength instrument $(637 \mathrm{~nm}$, Müller et al., 2011b) which uses a different approach to compensate for the artefacts associated with filterbased absorption methods (Petzold et al., 2005; Petzold and Schönlinner, 2004). Furthermore, the instrument differs from the PSAP because it changes filters automatically using a filter tape. The output of the instrument is equivalent black carbon (BCe). This was converted back to $\sigma_{\mathrm{AP}}$ from

$\sigma_{\mathrm{AP}}=\mathrm{MAC} \cdot \mathrm{BCe}$

using mass absorption cross-section (MAC) of $6.6 \mathrm{~m}^{2} \mathrm{~g}^{-1}$. A recent study by Hyvärinen et al. (2013) showed that the MAAP exhibits a filter change artefact at high BCe concentrations. The occurrence of the artefact depends on the rate 
of accumulation of BCe on the filter tape and thus a decreasing MAAP sample flow rate will decrease the number of filter change artefacts in MAAP. At Elandsfontein, the MAAP was operated at a $10 \mathrm{Lpm}$ flow rate. These periods were corrected according to the Hyvärinen et al. (2013) algorithm which led to a change of $-0.06 \%$ in $\sigma_{\mathrm{AP}}$ for all data.

\section{Results and discussion}

\subsection{Comparing the diluted PSAP with the non-diluted MAAP}

The performance of the diluted PSAP was evaluated by comparison to the MAAP. The PSAP data were interpolated to the MAAP wavelength $637 \mathrm{~nm}$ by using the AAEs obtained from the different algorithms. The respective relationships are shown in Fig. 3. The figure is based on PSAP data with a filter transmittance range of 0.7-1.0 (upper panel) and 0.40.7 (lower panel) for the V2010 and V2010avg correction algorithms, and the $\mathrm{O} 2010$ correction function. In the data set, $36 \%$ of the data were in the Tr range of $0.4-0.7$ and $52 \%$ in the range of $0.7-1.0$. The average filter change interval during the measurement period was 10 days that amounted to a total of 70 filter changes. On average, $\mathrm{Tr}$ had decreased to 0.54 (ranging from a maximum $\mathrm{Tr}$ of 0.99 to a minimum of 0.21 ) before it was changed. The dilution factor $\left(1+D_{\text {DIL }} / Q_{\mathrm{S}}\right)$ directly affects how often the filter needs to be changed. Thus, over 1000 filter changes could be reduced to 70 by diluting the sample.

The colour scale in Fig. 3 represents the number of data points at a given grid point. Since both instruments are associated with uncertainties, the linear regression shown in the figure was calculated using the bivariate method of Williamson-York (Cantrell, 2008; York et al., 2004). The data was weighted by the inverse value of the maximum value of each data pair. The maximum value of the data points was chosen for weighing because the signal needs to be weighed, not the noise. Thus, greater values are given a lower weight or they otherwise tend to dictate the slope of the regression. Figure 3 shows that the MAAP consistently showed higher $\sigma_{\mathrm{AP}}$ values than the PSAP in the Tr range of 0.7-1.0 (upper panel). The slopes (and standard deviation) of the linear regression for that $\operatorname{Tr}$ range are $0.83( \pm 0.28)$, $0.92( \pm 0.30)$ and $0.90( \pm 0.30)$ for the V2010, O2010 and V2010avg fits. In the Tr range of 0.4-0.7 (lower panel) the slopes are $0.95( \pm 0.35), 0.94( \pm 0.29)$ and $1.02( \pm 0.29)$ for the V2010, O2010 and V2010avg fits. The standard deviations (SD) were calculated from the standard error (SE) of the fits as $\mathrm{SD}=\mathrm{SE} \cdot \sqrt{ } n$.

The coefficients of determination $\left(R^{2}\right)$ for the different corrections in comparison to the MAAP, in the Tr range of $0.7-1.0$, were $0.89,0.90$ and 0.89 for the V2010, O2010 and V2010avg corrections. For the Tr range of $0.4-0.7, R^{2}$ did not significantly change in comparison to the $\mathrm{Tr}$ range of
0.7-1.0. In the lower $\operatorname{Tr}$ range of $0.4-0.7$, the $R^{2}$ values were 0.87 (V2010), 0.91 (O2010) and 0.86 (V2010avg). The correlation between the two instruments thus proved to be significant. The criterion which allowed the $Q_{\mathrm{DIL}}$ to deviate $5 \%$ from the desired value will add $\pm 4.7 \%$ uncertainty to $\sigma_{0, \mathrm{~S}}$ of Eq. (3). The criterion, however, cannot explain the observed spread of the data points around the regression line of Fig. 3; other factors are likely to contribute too.

Because the filter transmission correction functions differ, the $\sigma_{\mathrm{AP}}$ values should also be different and the difference should be a function of Tr. The values calculated using the V2010, V2010avg, and O2010 corrections were compared to the values measured with the MAAP (Fig. 4a) at $637 \mathrm{~nm}$ wavelength. It is evident that the V2010 correction gave lower values than the $\mathrm{O} 2010$ correction in the $\mathrm{Tr}$ range of 0.6-1.0. When Tr dropped below 0.6, the relationship was the opposite, which is in agreement with Virkkula (2010). The V2010avg and O2010 corrections yielded similar values at high $\mathrm{Tr}$ values which also contained the highest number of data points (Fig. 4b). Figure 4a is in agreement with the regression slopes presented in Fig. 3. In the Tr range of 0.71.0 , in Fig. $4 \mathrm{a}$, the $\sigma_{\mathrm{AP}}$ values calculated using the V2010 correction are below the O2010 and V2010avg curves. This is reflected in the slope of the regression in the upper panel of Fig. 3. At a Tr of 0.6, there is a crossover between the V2010 correction yielding lower values than the O2010. Below a $\mathrm{Tr}$ of 0.6 the V2010 correction yielded higher values than the O2010 correction. For the whole Tr range of 0.4-0.7, both the V2010 and O2010 have a similar slope, which is due to the crossover between the corrections at a $\operatorname{Tr}$ of 0.6. The local minimum at 0.35 of Fig. 4a is likely to be the result of fewer data points. More specifically, with fewer data points, the data is less dispersed in time which in turn can lead to overrepresentation of a particular part of the data. However, this should also apply for data points when $\operatorname{Tr}<0.3$, which does not seem to break the overall trend of Fig. 4a.

\subsection{Correction algorithms impact AAE}

The difference between the correction algorithms was investigated further by calculating the AAEs of the aerosol using different corrections algorithms for the same data set. The analysis showed that the use of different corrections algorithms yield very different AAEs. Figure 5 presents the average AAE as a function of Tr for the V2010 and V2010avg correction algorithms and for the $\mathrm{O} 2010$ correction function. Furthermore, $\sigma_{0}$ was included in the figure as a reference, which represents the AAE without any correction applied.

Figure 5 shows data from the Elandsfontein site and for a comparison AAEs calculated from PSAP data measured in a very different environment, the New England Air Quality Study (NEAQS) onboard the NOAA research ship Ronald H.Brown during July and August 2002, off the east coast of the United States. The NEAQS data are those presented by 

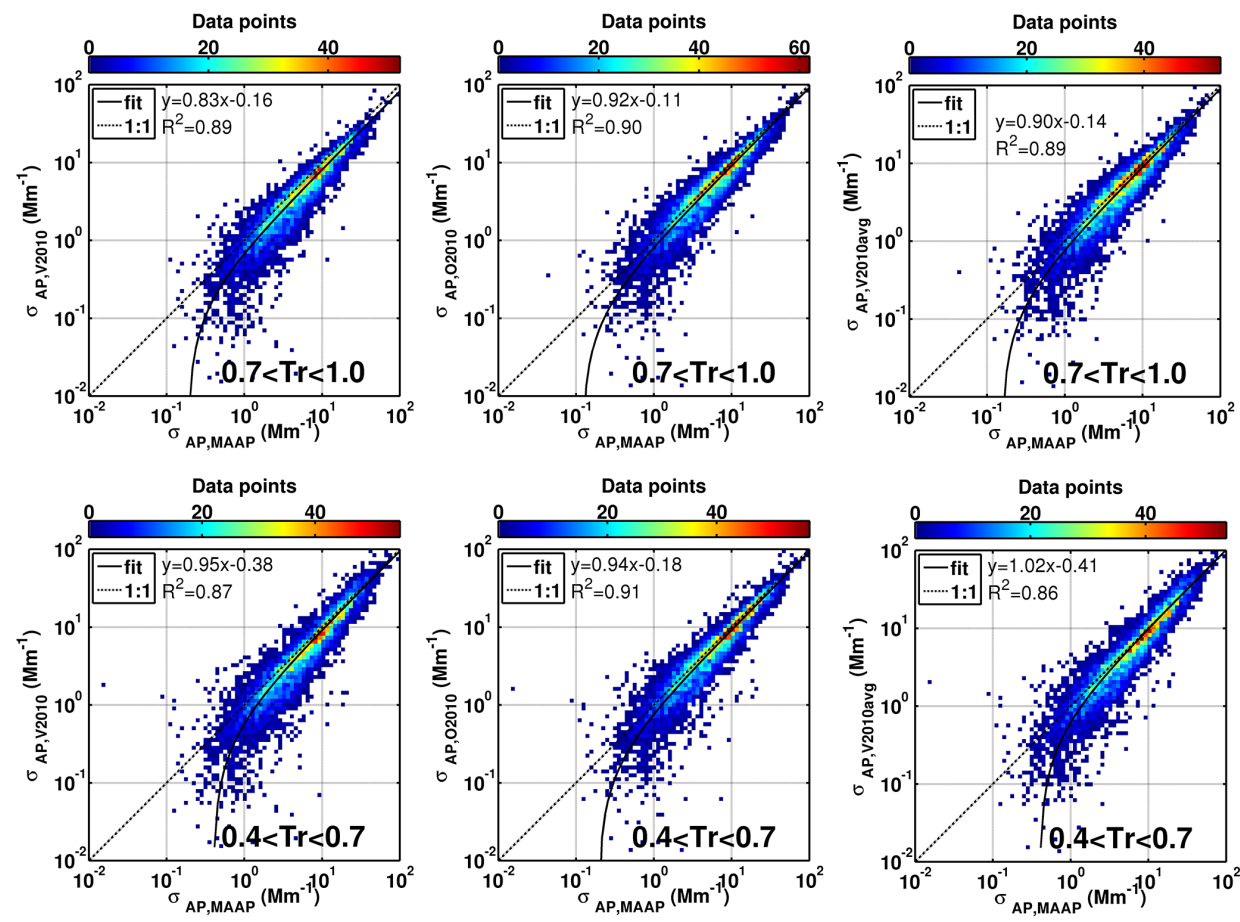

Figure 3. The relationship between light-absorption coefficients measured by the MAAP $\left(\sigma_{\mathrm{AP}, \mathrm{MAAP}}\right)$ and PSAP $\left(\sigma_{\mathrm{AP}, \mathrm{V} 2010}, \sigma_{\mathrm{AP}, \mathrm{O} 2010}\right.$ and $\left.\sigma_{\mathrm{AP}, \mathrm{V} 2010 \mathrm{avg}}\right)$. The upper and lower panels show data with a Tr range of 0.7-1.0 and 0.4-0.7, respectively. The integration time of the data plotted is $1 \mathrm{~h}$. The colour legends indicate the number of data points in the scatter plot at a given coordinate. The linear regression was done using the bivariate method.
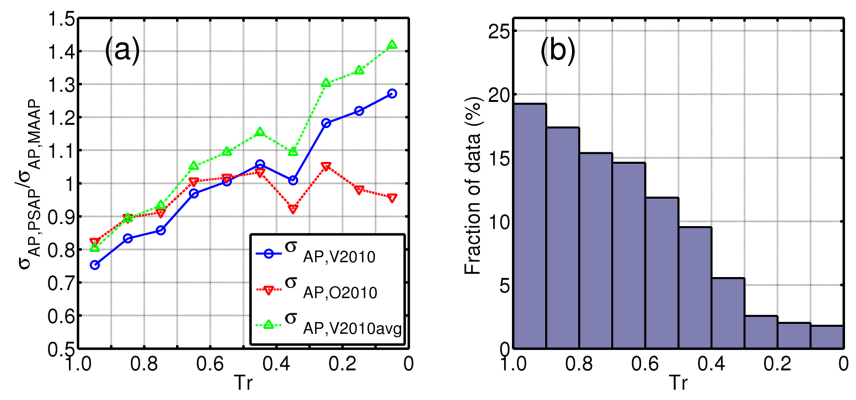

Figure 4. The influence of the PSAP's filter transmittance (Tr) on $\sigma_{\mathrm{AP}}$ in comparison to $\sigma_{\mathrm{AP}}$ from the MAAP and data coverage. (a) The median fraction of $\sigma_{\mathrm{AP}}$ calculated using the V2010 (blue), O2010 (red) and V2010avg (green) corrections in comparison to the MAAP ( $\left.\sigma_{\text {AP,MAAP }}\right)$. (b) The percentage of data points for a given Tr range.

Virkkula et al. (2005), but here the AAEs were calculated with the V2010 values for the respective corrections.

There are common features in the two data sets. First, Fig. 5a and b depict that the AAE is largely dependent on the correction used. Second, the AAE is, however to a lesser extent, dependent on $\mathrm{Tr}$, and to what extent seems to depend on the type of aerosol. Also shown in Fig. 5 is the AAE calculated from the wavelength-dependent ATN (Eq. 9). The filter correction algorithms and functions aim to compensate for the pre-deposited aerosol and incrementally derive the light absorption. This is argued to be the reason for the different shape of the AAE curve of ATN in Fig. 5 in comparison to $\sigma_{\mathrm{AP}}$. A general trend of AAEs calculated using ATN seems to be that lower Tr values will result in a lower AAE of the aerosol. For the AAEs calculated using different corrections, the trend is not as obvious as for AAEs calculated from ATN. For the Elandsfontein data (Fig. 5a), the AAEs of the V2010, V2010avg, and O2010 corrections tend to increase with low Tr values.

The average AAEs calculated from the Elandsfontein data using different corrections are summarised in Table 1. It should be emphasised that the number of data points decreases with $\mathrm{Tr}$, which will result in averages that do not equally represent the whole $\mathrm{Tr}$ range since more data exists at high $\operatorname{Tr}$ values.

At Elandsfontein, AAEs are distinctively higher than during the NEAQS campaign. In both data sets, the wavelengthdependent V2010 correction leads to the highest AAE. For the NEAQS data, V2010 results in average AAE of 1.25 which is slightly higher than the 1.19 presented in Virkkula et al. (2005), but all other corrections and $\sigma_{0}$ yield AAEs $<1$ (Fig. 5b). The AAEs that are below unity do not, however, imply that the corrections yield unphysical AAEs. Core-shell simulations have shown that a weakly or non-absorbing shell 


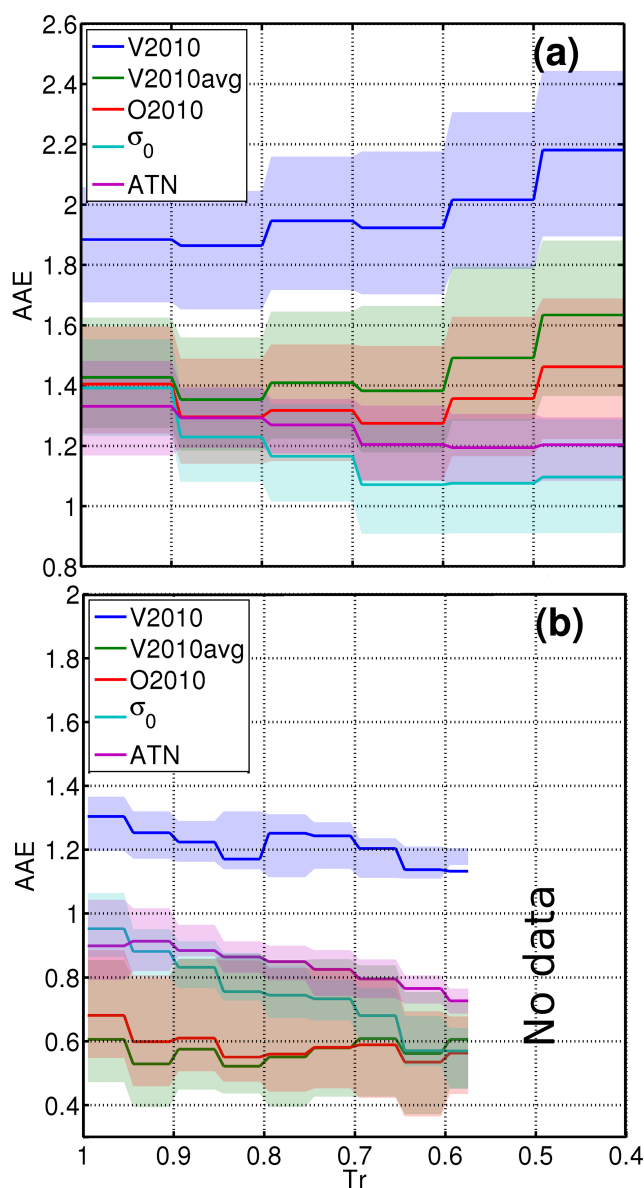

Figure 5. AAEs calculated using different correction algorithms, $\sigma_{0}$, and the AAEs calculated from ATN as a function of Tr. The solid lines represent the median AAE for the different corrections, $\sigma_{0}$ and ATN. The lines are ramped to indicate the Tr range the median was calculated from. The shaded coloured areas show the 25th to 75th percentile range of the AAEs lines with the same color. Panel (a) is based on Elandsfontein data and (b) is based on NEAQS 2002 campaign data. During the NEAQS 2002 campaign, the filter was changed at higher filter transmittances than at Elandsfontein. Hence there is no data when $\operatorname{Tr}<0.575$.

surrounding a BC core can lower the AAEs of particles substantially below unity (Gyawali et al., 2009; Lack and Cappa, 2010). The study by Gyawali et al. (2009) pointed out that care should be taken when drawing conclusions about the origin of the aerosol due to different AAEs depending on the core thickness surrounding the absorbing core.

Figure 5a shows that at Elandsfontein the AAEs derived from $\sigma_{\mathrm{AP}}$ calculated with the different corrections, although they yield different AAEs, do not greatly depend on $\operatorname{Tr}$ between 0.7 and 1.0. However, the AAEs calculated from $\sigma_{0}$ and ATN have a clear Tr dependency, they decrease with decreasing Tr. On the contrary, when $\operatorname{Tr}$ decreases below 0.7 , the AAEs calculated from $\sigma_{\mathrm{AP}}$ using different algorithms increase with decreasing Tr. Moreover, for the marine data
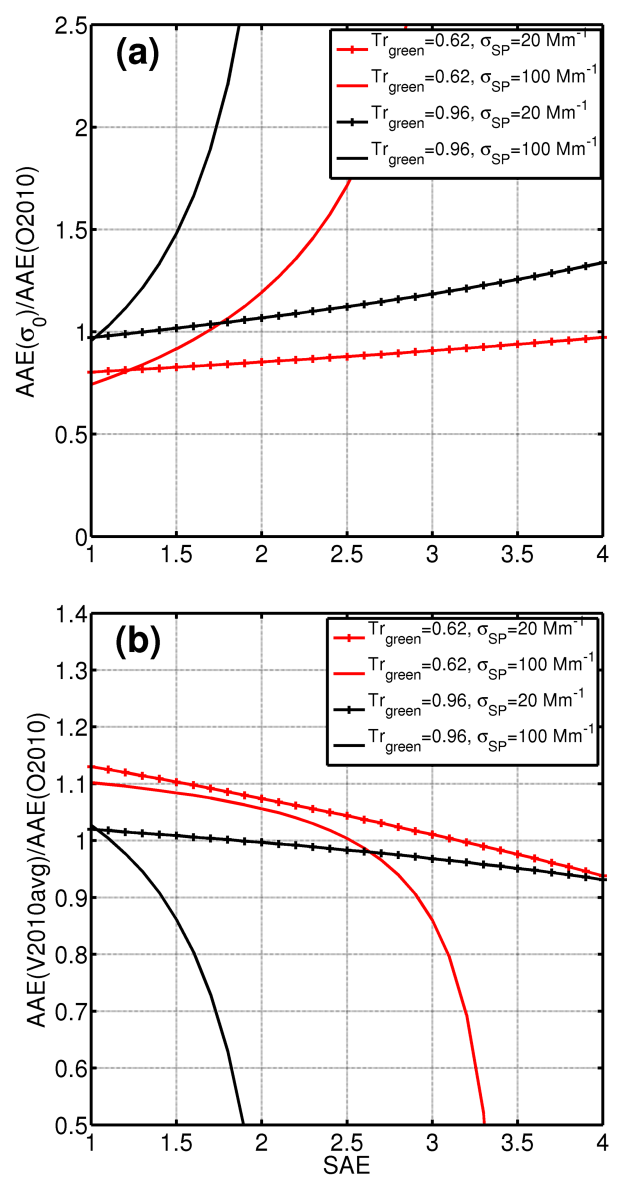

Figure 6. Simulation of the impact of SAE on the AAE calculated using different correction algorithms. The impact on the AAE was used assuming an AE of 1 when $\sigma_{0}$ was $10 \mathrm{Mm}^{-1}$ at $530 \mathrm{~nm}$. The upper panel (a) shows the ratio between the AE of $\sigma_{0}$ and the AAE calculated using O2010 correction. The lower panel (b) shows the ratio between AAE derived using the V2010avg and the O2010 corrections.

Table 1. AAEs calculated from the Elandsfontein data using different correction algorithms, $\sigma_{0}$ and ATN. The values in the parenthesises represent the AAE standard deviation.

\begin{tabular}{lll}
\hline Correction & \multicolumn{2}{c}{ AAE } \\
\hline & $0.4<\operatorname{Tr}<1.0$ & $0.7<\operatorname{Tr}<1.0$ \\
\hline V2010 & $1.96( \pm 0.44)$ & $1.90( \pm 0.38)$ \\
V2010avg & $1.43( \pm 0.42)$ & $1.39( \pm 0.36)$ \\
O2010 & $1.34( \pm 0.39)$ & $1.33( \pm 0.34)$ \\
$\sigma_{0}$ & $1.17( \pm 0.33)$ & $1.25( \pm 0.29)$ \\
ATN & $1.24( \pm 0.17)$ & $1.29( \pm 0.18)$ \\
\hline
\end{tabular}

(Fig. 5b), there is no increase in AAE when the Tr drops below 0.7 as there is for the Elandsfontein (Fig. 5a). This suggests that different aerosol types will impact the performance of the respective corrections. 
Laboratory studies have shown that liquid non-absorbing secondary organic aerosol (SOA) can change the radiative transfer of light and the optical path of the fiber filter substantially (Cappa et al., 2008). Moreover, Cappa et al. (2008) showed that semi-volatile SOA can condense and evaporate from filters and can thus change the liquid SOA coating of the fiber filters over time and thus impact the instrument response. A study by Lack et al. (2008) showed that the effect can be substantial even at low concentrations of SOA. However, the changes in absolute values $\sigma_{\mathrm{AP}}$, as reported by Cappa et al. (2008), when SOA concentrations change rapidly, are likely to be dampened by the dilution flow arrangements in the present study. The absolute filter of the setup in the dilution loop will likely dampen abrupt changes in the SOA concentration in the sampling line due to the large surface area of the filter from which SOA could partition between gas phase and liquid phase. It should be acknowledged that a buildup of liquid SOA in filter can change the radiative transfer of light through the filter, and what the wavelength dependence of the bias is remains unknown. With large SOA loadings, the wavelength dependence of SOAsoaked fiber filters could potentially change the wavelength dependence of multiple scattering inside filters. This effect could also change the AAEs dependence on how deeply the pre-deposited particles have been embedded into the filter (Lack et al., 2009; Nakayama et al., 2010).

The absolute change in AAEs as a function of Tr for the different data sets suggests that the praxis to change filters at a certain Tr will affect the AAEs of the data. For the Elandsfontein data, the median AAEs of Fig. 5, changed by 0.04 (V2010), -0.13 (O2010), -0.04 (V2010avg), -0.32 ( $\left.\sigma_{0}\right)$ and -0.13 (ATN) when the Tr dropped from 1.0 to 0.7 . For the marine NEAQS 2002 data, the AAEs changed by -0.06 (V2010), -0.10 (O2010), -0.03 (V2010avg), -0.22 ( $\left.\sigma_{0}\right)$ and -0.07 (ATN) when Tr dropped from 1.0 to 0.7 . For both data sets, AAEs calculated from $\sigma_{0}$ and ATN experienced the greatest $\mathrm{Tr}$ dependency.

The AAEs from the wavelength-dependent V2010 algorithm are highest because all the constants in the algorithm are wavelength dependent. On the contrary, it is not that obvious why the non-wavelength-dependent methods do not yield the same AAEs. For instance, for the Elandsfontein data the V2010avg correction algorithm yielded higher AAEs than the $\mathrm{O} 2010$ correction function, as opposed to the behaviour of the NEAQS data set (Fig. 5). Moreover, the AAEs of $\sigma_{0}$ were consistently lower than those calculated from $\sigma_{\text {AP }}$ using different corrections at Elandsfontein (Fig. 5a), whereas the AAEs of $\sigma_{0}$ was for the most part greater than the AAEs calculated using the V2010avg and O2010 corrections during NEAQS (Fig. 5b). The order of the AAEs in the nonwavelength-dependent corrections (O2010 and V2010avg) is argued to be a result of different scattering Ångström exponent (SAE) of the aerosol. The corrections depend on the scattering coefficients, so it is reasonable that the wavelength dependence of scattering also has an effect on AAE. The av- erage SAE was 1.55 at Elandsfontein whereas the SAE of the NEAQS 2002 aerosol was considerably higher, between 2 and 3 (Virkkula et al., 2005). This suggests that the size of the particles at Elandsfontein were larger than those measured during the NEAQS 2002 campaign.

The AAE dependence on the SAE of the aerosol for the V2010avg and O2010 corrections and the AAE calculated from $\sigma_{0}$ was analysed by making a simple simulation. $\sigma_{0}$ at $\lambda=530 \mathrm{~nm}$ was set to $10 \mathrm{Mm}^{-1}$ and $\operatorname{AAE}\left(\sigma_{0}\right)=1$ and the transmittances at the same wavelength to 0.96 and 0.62 , representing two ranges of filter loading. The above $\sigma_{0}$ and $\mathrm{Tr}$ values were taken from real data measured at Elandsfontein; the $\operatorname{AAE}\left(\sigma_{0}\right)$ was set. The corrections were calculated for a case with low $\sigma_{\mathrm{SP}}=20 \mathrm{Mm}^{-1}$ at the nephelometer wavelength $\lambda=550 \mathrm{~nm}$ representing an aerosol with a low SSA and for a case representing a high $\operatorname{SSA}\left(\sigma_{\mathrm{SP}}=100 \mathrm{Mm}^{-1}\right)$; SAE was varied in the range of $1-4$, and the scattering coefficients were extrapolated to the PSAP wavelengths. The absorption coefficients were calculated using the V2010avg and $\mathrm{O} 2010$ algorithms and the AAEs from them.

The results of the simulation are shown in Fig. 6. Figure 6a shows that the scattering correction results in a different AAE than that calculated from the non-scattering-corrected $\sigma_{0}$ even though the correction itself is not wavelength dependent. The figure also shows that the effect on AAE depends on $\mathrm{Tr}$, scattering properties of the aerosol $\left(\sigma_{\mathrm{SP}}\right.$ and SAE $)$ and SSA. The impact is not as dramatic for the case with a low SSA since the scattering correction is consequently less in comparison to the case with high SSA values.

When comparing the AAEs calculated using the V2010avg correction algorithm and the O2010 correction function in the same manner, the difference between the AAEs calculated using these corrections are not the same. Figure $6 \mathrm{~b}$ shows that for different aerosol types (either a high or a low SSA and a range of SAE values) the corrections can yield very different AAEs. It should be noted, that Fig. 6 depends on Tr, which inherently is a result of the type of aerosol particles that burden the filter. Furthermore, there is likely a cross-dependency between Tr and SAE which is not considered if Fig. 6. The different behaviour of the V2010avg and O2010 corrections with respect to each other, and in comparison to $\sigma_{0}$ can be explained by a different aerosol type between the cases of high and low SSA. The analysis was restricted to V2010avg and O2010 only since V2010 consistently showed larger AAE values than the other corrections.

\subsection{AAE as a function of SSA}

The surface plots in Fig. 7 present the correlation between the AAE and the SSA. The figures were smoothened using a $3 \times 3$ matrix with equal weights for the surrounding grid points to make the interpretation of the figure more clear. The grid interval in the figure is 0.004 on the $x$ axis and 0.05 on the $y$ axis. The SSA of the aerosols was calculated by using the MAAP and the Nephelometer (interpolated to a $637 \mathrm{~nm}$ 

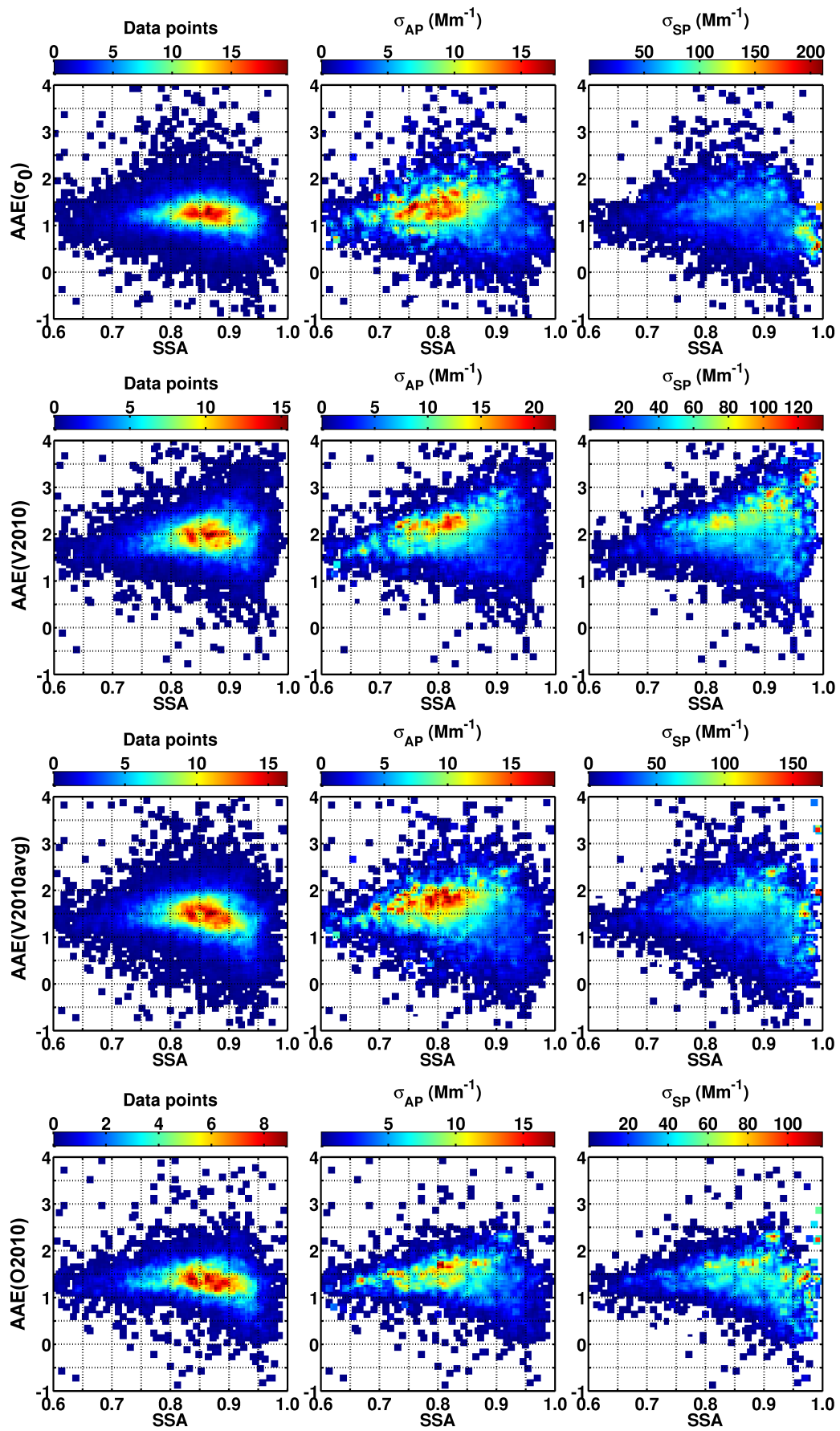

Figure 7. AAE as a function of SSA, colour coded with the number of data points $\sigma_{\mathrm{AP}}$ and $\sigma_{\mathrm{SP}}$. The SSA was calculated using MAAP and Nephelometer data at $637 \mathrm{~nm}$ wavelength to fix the $x$ axis for all subplots. The AAE ( $y$ axis) was calculated for $\sigma_{0}$ (first rows), V2010 (second row), V2010avg (third row) and for the O2010 (bottom row) correction. MAAP data was used for colour coding $\sigma_{\mathrm{AP}}$ in the middle column.

wavelength) data in order to make the comparison between the different corrections consistent. Thus, AAEs using different corrections will be given the same SSA regardless of the correction used. Figure 7 shows again that the different corrections were prone to yield higher AAEs than when calculated directly from $\sigma_{0}$.

In the first column, distinct differences are observed when comparing the AAEs calculated using $\sigma_{\mathrm{AP}}$ from the V2010, V2010avg and O2010 corrections, and $\sigma_{0}$. The AAEs of $\sigma_{0}$ 
were mostly in the range of $0.84-1.50$. AAEs calculated with the V2010 correction were mostly in the range of 1.52-2.40, whereas the V2010avg correction yielded AAEs in the range of 1.01-1.85. AAEs calculated with the O2010 correction were in the range of $0.95-1.73$. It should be noted that the O2010 correction only included data that were measured at a $\mathrm{Tr}$ above 0.7 , while the V2010avg and V2010 corrections included data with a Tr above 0.4 .

The second and third column of Fig. 7 depicts that the most frequently occurring range in AAE and SSA did not always coincide with the highest $\sigma_{\mathrm{AP}}$ and $\sigma_{\mathrm{SP}}$ values. The high $\sigma_{\mathrm{AP}}$ values were for the most part observed outside of the most frequently occurring combination of SSA and AAE values. However, high $\sigma_{\mathrm{AP}}$ values were associated with a lower SSA, suggesting that the aerosol was not long-range transported biomass burning smoke; a higher SSA would be expected for such an aerosol. Furthermore, high values of $\sigma_{\mathrm{SP}}$ did not either fall into the more frequently occurring combination of SSA and AAE at the site. The areas that show the highest $\sigma_{\mathrm{AP}}$ values are not the coordinates that are associated with the highest $\sigma_{\mathrm{SP}}$ values, suggesting different sources. It should be noted that the middle and right column of the figure should be interpreted in conjunction with the number of data points associated with the coordinate keeping in mind that the figure is smoothened to make the general features of the aerosol more apparent.

All corrections assume that apparent absorption is a certain fraction of the $\sigma_{\mathrm{SP}}$. A high SSA combined with high $\sigma_{\mathrm{SP}}$ seems to scatter events throughout the AAE axis depending on the correction used; by how much is likely to be affected by the state of the filter when the event occurred. In other words, the different corrections are prone towards different AAEs given that the SSA and $\sigma_{\text {SP }}$ are high, which is in agreement with Fig. 6.

\subsection{Corrections' impact OC estimates}

The AAEs were next used to estimate the impact that different corrections have on the estimation of OC contribution to aerosol light absorption, as described in Sect. 2.3.3. Figure 8 highlights the differences between corrections algorithms, functions and different approaches when AAEs are used to estimate the amount of absorption by OC. Figure $8 \mathrm{a}$ depicts the absorption attributed to $\mathrm{BC}$ with respect to the total absorption by the aerosol used in Eqs (10) and (11) using the AAE values in Table 1 in the Tr range of 0.7-1.0.

The figure shows the $f_{\mathrm{OC}}(\mathrm{abs})$ and $f_{\mathrm{OC}}(\mathrm{ATN})$ as a function of wavelength for the different correction algorithms. From the figure it is evident that there is a significant difference in the calculated $f_{\mathrm{OC}}$ by using AAE based on different correction schemes. The correction function that gives the highest AAE also predicts the highest contribution of absorption by OC. The $f_{\text {OC }}$ calculated using AAE with the V2010 correction was a factor of approximately 3 higher than if $f_{\mathrm{OC}}$ was calculated from the non-corrected $\sigma_{0}$. Moreover, the $f_{\mathrm{OC}}$
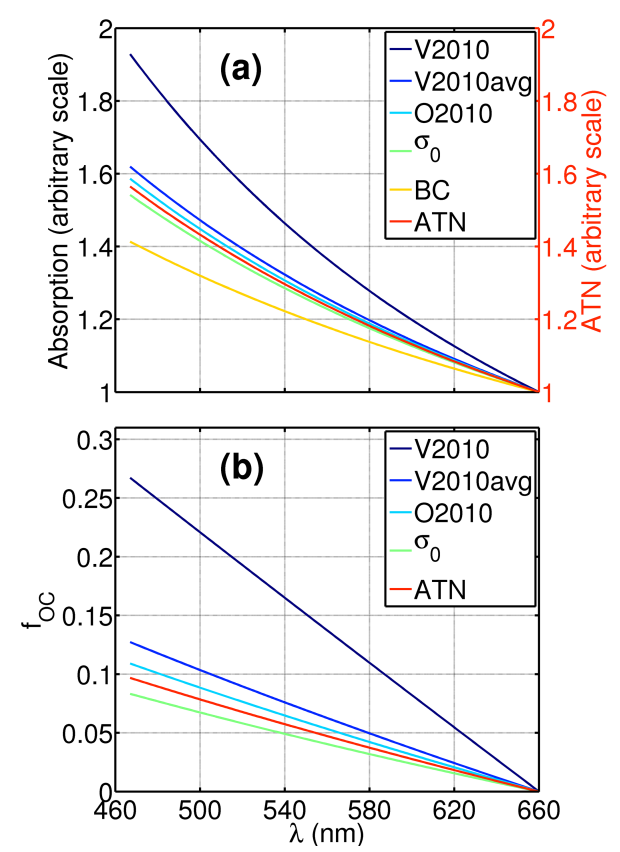

Figure 8. The difference in the wavelength dependency of absorption using different approaches for deriving AAEs and their impact on the estimated fraction of absorption by OC $\left(f_{\mathrm{OC}}\right)$. (a) The wavelength dependency of absorption and filter attenuation ATN calculated using the AAEs of Table 1. At $660 \mathrm{~nm}$ all absorption is attributed to BC with an AAE of unity. (b) The wavelength dependency of $f_{\mathrm{OC}}$ which is the fraction of absorption that exceeds the absorption of BC from Eqs. (12a) and (12b).

of the V2010avg and O2010 corrections were roughly 38 and $63 \%$ larger than if no correction was used.

As discussed earlier, $f_{\mathrm{OC}}(\mathrm{abs})$ are based on subsequent measurements using the same filter whereas the $f_{\mathrm{OC}}(\mathrm{ATN})$ can be considered to be one long measurement until $\mathrm{Tr}$ has dropped to a certain value. In the study by Kirchstetter and Thatcher (2012) the ATN ranged between 2 and 23 for most of the samples. That is equivalent to a $\mathrm{Tr}$ ranging between 0.98 and 0.79 , see Eq. (9). In this study, the average Tr of the filter (in the Tr range of 0.7-1.0) was 0.86. Thus, the study of Kirchstetter and Thatcher (2012) was not completely different in terms of filter loadings than this study. When comparing $f_{\mathrm{OC}}(\mathrm{ATN})$ to $f_{\mathrm{OC}}\left(\sigma_{0}\right), f_{\mathrm{OC}}(\mathrm{ATN})$ was $17 \%$ higher than $f_{\mathrm{OC}}\left(\sigma_{0}\right)$. This relationship, however, depends on the type of aerosol and the $\operatorname{Tr}$ of the filters (Fig. 5). It should be noted, however, that this simple approach does not differentiate between light absorption by $\mathrm{BrC}$ and that by mineral dust.

Furthermore, the true AAE of the light-absorbing constituent at a wavelength of $660 \mathrm{~nm}$ is not known. The estimation of $f_{\mathrm{OC}}$ in Fig. $8 \mathrm{~b}$ is thus solely based on the assumption that the AAE equals unity in the wavelength range of $467-660 \mathrm{~nm}$ for the non-OC aerosol. As discussed earlier, the AAE depends on the mixing state of the light-absorbing constituents (Gyawali et al., 2009; Lack and Kappa, 2010). The 
actual AAE of the aerosol, however, can range from 0.55 to 1.7 in extreme cases (Lack and Langridge, 2013). Furthermore, the accuracy of the method of attributing light absorption to $\mathrm{BrC}$ using AAEs depends on the fraction of $\mathrm{BrC}$ absorption to total absorption (Lack and Langridge, 2013).

\section{Conclusions}

The study showed a means by which the sample air of the PSAP can be diluted. After a dilution of $1: 14$, the correlation coefficient between the diluted PSAP, and a non-diluted MAAP was 0.9 after post-processing the PSAP data to a temporal resolution of $1 \mathrm{~h}$. The bivariate regression slopes were between 0.83 and 0.92 depending on the correction algorithm used. The extent of the dilution of the sampled air extends the need to change filters in the PSAP to expand the applicability of the instrument. The dilution setup presented here can benefit stations in remote areas or areas that suffer from high levels of pollution, without significantly compromising data quality or introduce noise. A further improvement of the dilution arrangement could be to have a mass-flow controller for the dilution flow to provide more accurate data for the dilution calculations.

The AAEs calculated from the data showed a large dependence on the algorithm used to convert the uncorrected "raw" absorption coefficient $\sigma_{0}$ to the aerosol absorption coefficient $\sigma_{\mathrm{AP}}$. The study showed that the correction algorithms used for PSAP measurements can lead to conflicting conclusions about aerosols using the same data. Depending on the algorithm used to calculate the AAE, the average AAE of aerosols varied between 1.33 and 1.96. The lower value suggests urban aerosol pollution and the higher suggests biomass burning aerosols.

The highest (1.96) AAEs at Elandsfontein were obtained from the $\sigma_{\mathrm{AP}}$ calculated with the wavelength-dependent V2010 algorithm and the lowest from $\sigma_{0}$ (1.17). When the AAEs were calculated from a marine aerosol data, the order changed: again the V2010 algorithm yielded the highest values, but the lowest ones were obtained from $\sigma_{\mathrm{AP}}$ calculated with non-wavelength-dependent algorithms. The fact that the wavelength-dependent V2010 algorithm yields greater AAEs depends on the wavelength dependency of both the loading correction and the scattering correction. It cannot be determined from this analysis which of them is the most true but some evaluation can be made. If an algorithm for calculating $\sigma_{\mathrm{AP}}$ from $\sigma_{0}$ worked perfectly at all transmittances (Tr), the AAE should not depend on Tr. With this criterium the AAE calculated directly from $\sigma_{0}$ is not the preferable choice because it decreased clearly with decreasing Tr. Also, the AAE calculated directly from the Tr decreased with a decreasing $\mathrm{Tr}$, even though less than that calculated from $\sigma_{0}$. The conclusion is that spectral attenuation measurements from filter samples may yield lower AAE values when the filters are heavily loaded than AAE values calculated from lightabsorption measurements derived using correction schemes.

The differences in AAEs calculated using different correction algorithms can be as significant as the thickness of the shell that can encapsulate an absorbing BC core. Thus, in the quest to distinguish between urban pollution and biomass burning type aerosol one should also consider the influence of the correction used and the uncertainties associated with them.

Furthermore, the difference in AAEs can also result in large differences when estimating the contribution of $\mathrm{OC}$ to light absorption. Depending on the algorithm used in this study, the estimated fraction of absorption by OC ranged between 0.27 and 0.11 at a wavelength of $467 \mathrm{~nm}$. Moreover, if no correction function was used for the data, the OC fraction was even lower (0.08).

Ideally, AAEs should be determined with multiwavelength absorption measurements on the aerosol while the aerosol is still suspended, such as with photoacoustic measurements or the extinction-minus-scattering method. These methods would be valuable tools for characterising how the correction algorithms perform at different sites at multiple wavelengths. The study would need to include the deposition of liquid SOA to determine how the radiative transfer at multiple wavelengths would affect the AAEs in a similar manner that was conducted by Lack et al. (2008).

Acknowledgements. The project was funded by the European commission 6th Framework programme project EUCAARI. The authors greatly acknowledge the Academy of Finland Centre of Excellence program (project nos. 1118615 and 272041). Eskom and Sasol Ltd. are acknowledged for logistical, financial and on-site support.

Edited by: O. Dubovik

\section{References}

Amante, C. and Eakins, B. W.: ETOPO1 1 Arc-Minute Global Relief Model: Procedures, Data Sources and Analysis, NOAA Technical Memorandum NESDIS NGDC-24, 19 March 2009.

Andreae, M. O. and Gelencsér, A.: Black carbon or brown carbon? The nature of light-absorbing carbonaceous aerosols, Atmos. Chem. Phys., 6, 3131-3148, doi:10.5194/acp-6-3131-2006, 2006.

Bergstrom, R. W., Pilewskie, P., Russell, P. B., Redemann, J., Bond, T. C., Quinn, P. K., and Sierau, B.: Spectral absorption properties of atmospheric aerosols, Atmos. Chem. Phys., 7, 5937-5943, doi:10.5194/acp-7-5937-2007, 2007.

Bond, T. C., Anderson, T. L., and Campbell, D.: Calibration and intercomparison of filter-based measurements of visible light absorption by aerosols, Aerosol. Sci. Technol., 30, 582-600, 1999.

Bond, T. C., Doherty, S. J., Fahey, D. W., Forster, P. M., Berntsen, T., DeAngelo, B. J., Flanner, M. G., Ghan, S., Kärcher, B., Koch, D., Kinne, S., Kondo, Y., Quinn, P. K., Sarofim, M. C., Schultz, 
M. G., Schulz, M., Venkataraman, C., Zhang, H., Zhang, S., Bellouin, N., Guttikunda, S. K., Hopke, P. K., Jacobson, M. Z., Kaiser, J. W., Klimont, Z., Lohmann, U., Schwarz, J. P., Shindell, D., Storelvmo, T., Warren, S. G., and Zender, C. S.: Bounding the role of black carbon in the climate system: A scientific assessment, J. Geophys. Res.-Atmos., 118, 5380-5552, doi:10.1002/jgrd.50171, 2013.

Cantrell, C. A.: Technical Note: Review of methods for linear leastsquares fitting of data and application to atmospheric chemistry problems, Atmos. Chem. Phys., 8, 5477-5487, doi:10.5194/acp8-5477-2008, 2008.

Cappa, C. D., Lack, D. A., Burkholder, J. B., and Ravishankara, A. R.: Bias in Filter-Based Aerosol Light Absorption Measurements Due to Organic Aerosol Loading: Evidence from Laboratory Measurements, Aerosol Sci. Technol., 42, 1022-1032, doi:10.1080/02786820802389285, 2008.

Clarke, A., McNaughton, C., Kapustin, V., Shinozuka, Y., Howell, S., Dibb, J., Zhou, J., Anderson, B., Brekhovskikh, V., Turner, H., and Pinkerton, M.: Biomass burning and pollution aerosol over North America: Organic components and their influence on spectral optical properties and humidification response, J. Geophys. Res.-Atmos., 112, D12S18, doi:10.1029/2006JD007777, 2007.

Collaud Coen, M., Weingartner, E., Schaub, D., Hueglin, C., Corrigan, C., Henning, S., Schwikowski, M., and Baltensperger, U.: Saharan dust events at the Jungfraujoch: detection by wavelength dependence of the single scattering albedo and first climatology analysis, Atmos. Chem. Phys., 4, 2465-2480, doi:10.5194/acp4-2465-2004, 2004.

Collaud Coen, M., Weingartner, E., Apituley, A., Ceburnis, D., Fierz-Schmidhauser, R., Flentje, H., Henzing, J. S., Jennings, S. G., Moerman, M., Petzold, A., Schmid, O., and Baltensperger, U.: Minimizing light absorption measurement artifacts of the Aethalometer: evaluation of five correction algorithms, Atmos. Meas. Tech., 3, 457-474, doi:10.5194/amt-3-457-2010, 2010.

Gyawali, M., Arnott, W. P., Lewis, K., and Moosmüller, H.: In situ aerosol optics in Reno, NV, USA during and after the summer 2008 California wildfires and the influence of absorbing and non-absorbing organic coatings on spectral light absorption, Atmos. Chem. Phys., 9, 8007-8015, doi:10.5194/acp-9-8007-2009, 2009.

Haywood, J. and Boucher, O.: Estimates of the direct and indirect radiative forcing due to tropospheric aerosols: A review, Rev. Geophys., 38, 513-543, 2000.

Hoffer, A., Gelencsér, A., Guyon, P., Kiss, G., Schmid, O., Frank, G. P., Artaxo, P., and Andreae, M. O.: Optical properties of humic-like substances (HULIS) in biomass-burning aerosols, Atmos. Chem. Phys., 6, 3563-3570, doi:10.5194/acp-6-3563-2006, 2006.

Hyvärinen, A.-P., Vakkari, V., Laakso, L., Hooda, R. K., Sharma, V. P., Panwar, T. S., Beukes, J. P., van Zyl, P. G., Josipovic, M., Garland, R. M., Andreae, M. O., Pöschl, U., and Petzold, A.: Correction for a measurement artifact of the Multi-Angle Absorption Photometer (MAAP) at high black carbon mass concentration levels, Atmos. Meas. Tech., 6, 81-90, doi:10.5194/amt-681-2013, 2013.

Kirchstetter, T. W. and Thatcher, T. L.: Contribution of organic carbon to wood smoke particulate matter absorption of solar radiation, Atmos. Chem. Phys., 12, 6067-6072, doi:10.5194/acp-126067-2012, 2012.
Kirchstetter, T. W., Novakov, T., and Hobbs, P. V.: Evidence that the spectral dependence of light absorption by aerosols is affected by organic carbon, J. Geophys. Res.-Atmos., 109, D21208, doi:10.1029/2004JD004999, 2004.

Laakso, L., Vakkari, V., Virkkula, A., Laakso, H., Backman, J., Kulmala, M., Beukes, J. P., van Zyl, P. G., Tiitta, P., Josipovic, M., Pienaar, J. J., Chiloane, K., Gilardoni, S., Vignati, E., Wiedensohler, A., Tuch, T., Birmili, W., Piketh, S., Collett, K., Fourie, G. D., Komppula, M., Lihavainen, H., de Leeuw, G., and Kerminen, V.-M.: South African EUCAARI measurements: seasonal variation of trace gases and aerosol optical properties, Atmos. Chem. Phys., 12, 1847-1864, doi:10.5194/acp-12-1847-2012, 2012.

Lack, D. A. and Cappa, C. D.: Impact of brown and clear carbon on light absorption enhancement, single scatter albedo and absorption wavelength dependence of black carbon, Atmos. Chem. Phys., 10, 4207-4220, doi:10.5194/acp-10-4207-2010, 2010.

Lack, D. A. and Langridge, J. M.: On the attribution of black and brown carbon light absorption using the Ångström exponent, Atmos. Chem. Phys., 13, 10535-10543, doi:10.5194/acp13-10535-2013, 2013.

Lack, D. A., Lovejoy, E. R., Baynard, T., Pettersson, A., and Ravishankara, A. R.: Aerosol Absorption Measurement using Photoacoustic Spectroscopy: Sensitivity, Calibration, and Uncertainty Developments, Aerosol Sci. Technol., 40, 697-708, doi:10.1080/02786820600803917, 2006.

Lack, D. A., Cappa, C. D., Covert, D. S., Baynard, T., Massoli, P., Sierau, B., Bates, T. S., Quinn, P. K., Lovejoy, E. R., and Ravishankara, A. R.: Bias in Filter-Based Aerosol Light Absorption Measurements Due to Organic Aerosol Loading: Evidence from Ambient Measurements, Aerosol Sci. Technol., 42, 1033-1041, doi:10.1080/02786820802389277, 2008.

Lack, D. A., Cappa, C. D., Cross, E. S., Massoli, P., Ahern, A. T., Davidovits, P. and Onasch, T. B.: Absorption Enhancement of Coated Absorbing Aerosols: Validation of the Photo-Acoustic Technique for Measuring the Enhancement, Aerosol Sci. Technol., 43, 1006-1012, doi:10.1080/02786820903117932, 2009.

Lohmann, U. and Feichter, J.: Global indirect aerosol effects: a review, Atmos. Chem. Phys., 5, 715-737, doi:10.5194/acp-5-7152005, 2005.

Moosmüller, H., Chakrabarty, R. K., and Arnott, W. P.: Aerosol light absorption and its measurement: A review, J. Quant. Spectrosc. Radiat. Trans, 110, 844-878, doi:10.1016/j.jqsrt.2009.02.035, 2009.

Moosmüller, H., Chakrabarty, R. K., Ehlers, K. M., and Arnott, W. P.: Absorption Ångström coefficient, brown carbon, and aerosols: basic concepts, bulk matter, and spherical particles, Atmos. Chem. Phys., 11, 1217-1225, doi:10.5194/acp-11-12172011, 2011.

Müller, T., Laborde, M., Kassell, G., and Wiedensohler, A.: Design and performance of a three-wavelength LED-based total scatter and backscatter integrating nephelometer, Atmos. Meas. Tech., 4, 1291-1303, doi:10.5194/amt-4-1291-2011, 2011a.

Müller, T., Henzing, J. S., de Leeuw, G., Wiedensohler, A., Alastuey, A., Angelov, H., Bizjak, M., Collaud Coen, M., Engström, J. E., Gruening, C., Hillamo, R., Hoffer, A., Imre, K., Ivanow, P., Jennings, G., Sun, J. Y., Kalivitis, N., Karlsson, H., Komppula, M., Laj, P., Li, S.-M., Lunder, C., Marinoni, A., Martins dos Santos, S., Moerman, M., Nowak, A., Ogren, J. A., Petzold, A., Pichon, J. M., Rodriquez, S., Sharma, S., Sheridan, 
P. J., Teinilä, K., Tuch, T., Viana, M., Virkkula, A., Weingartner, E., Wilhelm, R., and Wang, Y. Q.: Characterization and intercomparison of aerosol absorption photometers: result of two intercomparison workshops, Atmos. Meas. Tech., 4, 245-268, doi:10.5194/amt-4-245-2011, 2011 b.

Müller, T., Virkkula, A., and Ogren, J. A.: Constrained two-stream algorithm for calculating aerosol light absorption coefficient from the Particle Soot Absorption Photometer, Atmos. Meas. Tech., 7, 4049-4070, doi:10.5194/amt-7-4049-2014, 2014.

Nakayama, T., Kondo, Y., Moteki, N., Sahu, L. K., Kinase, T., Kita, K., and Matsumi, Y.: Size-dependent correction factors for absorption measurements using filter-based photometers: PSAP and COSMOS, J. Aerosol Sci., 41, 333-343, doi:10.1016/j.jaerosci.2010.01.004, 2010.

Ogren, J. A.: Comment on "Calibration and Intercomparison of Filter-Based Measurements of Visible Light Absorption by Aerosols", Aerosol. Sci. Technol., 44, 589-591, doi:10.1080/02786826.2010.482111, 2010.

Petzold, A. and Schönlinner, M.: Multi-angle absorption photometry-a new method for the measurement of aerosol light absorption and atmospheric black carbon, J. Aerosol Sci., 35, 421-441, doi:10.1016/j.jaerosci.2003.09.005, 2004.

Petzold, A., Schloesser, H., Sheridan, P. J., Arnott, W. P., Ogren, J. A., and Virkkula, A.: Evaluation of multiangle absorption photometry for measuring aerosol light absorption, Aerosol. Sci. Technol., 39, 40-51, doi:10.1080/027868290901945, 2005.

Petzold, A., Rasp, K., Weinzierl, B., Esselborn, M., Hamburger, T., Dörnbrack, A., Kandler, K., Schütz, L., Knippertz, P., Fiebig, M., and Virkkula, A.: Saharan dust absorption and refractive index from aircraft-based observations during SAMUM 2006, Tellus B, 61, 118-130, doi:10.1111/j.1600-0889.2008.00383.x, 2009.

Prospero, J. M.: Long-term measurements of the transport of African mineral dust to the southeastern United States: Implications for regional air quality, J. Geophys. Res.-Atmos., 104, 15917-15927, doi:10.1029/1999JD900072, 1999.

Russell, P. B., Bergstrom, R. W., Shinozuka, Y., Clarke, A. D., DeCarlo, P. F., Jimenez, J. L., Livingston, J. M., Redemann, J., Dubovik, O., and Strawa, A.: Absorption Angstrom Exponent in AERONET and related data as an indicator of aerosol composition, Atmos. Chem. Phys., 10, 1155-1169, doi:10.5194/acp-101155-2010, 2010.
Schnaiter, M., Gimmler, M., Llamas, I., Linke, C., Jäger, C., and Mutschke, H.: Strong spectral dependence of light absorption by organic carbon particles formed by propane combustion, Atmos. Chem. Phys., 6, 2981-2990, doi:10.5194/acp-6-2981-2006, 2006.

Schuster, G., Dubovik, O., and Holben, B.: Angstrom exponent and bimodal aerosol size distributions, J. Geophys. Res.-Atmos., 111 D07207, doi:10.1029/2005JD006328, 2006.

Springston, S. R. and Sedlacek III, A. J.: Noise characteristics of an instrumental particle absorbance technique, Aerosol. Sci. Technol., 41, 1110-1116, doi:10.1080/02786820701777457, 2007.

Tuch, T. M., Haudek, A., Müller, T., Nowak, A., Wex, H., and Wiedensohler, A.: Design and performance of an automatic regenerating adsorption aerosol dryer for continuous operation at monitoring sites, Atmos. Meas. Tech., 2, 417-422, doi:10.5194/amt-2-417-2009, 2009.

Virkkula, A.: Correction of the Calibration of the 3-wavelength Particle Soot Absorption Photometer (3 PSAP), Aerosol Sci. Technol., 44, 706-712, doi:10.1080/02786826.2010.482110ER, 2010.

Virkkula, A., Ahlquist, N. C., Covert, D. S., Arnott, W. P., Sheridan, P. J., Quinn, P. K., and Coffman, D. J.: Modification, calibration and a field test of an instrument for measuring light absorption by particles, Aerosol Sci. Technol., 39, 68-83, doi:10.1080/027868290901963ER, 2005.

Weingartner, E., Saathoff, H., Schnaiter, M., Streit, N., Bitnar, B., and Baltensperger, U.: Absorption of light by soot particles: determination of the absorption coefficient by means of aethalometers, J. Aerosol Sci., 34, 1445-1463, doi:10.1016/S00218502(03)00359-8, 2003.

York, D., Evensen, N. M., Martinez, M. L., and Delgado, J. D. B.: Unified equations for the slope, intercept, and standard errors of the best straight line, Am. J. Phys, 72, 367-375, doi:10.1119/1.1632486, 2004. 